\title{
Rancang Bangun dan Analisa Kinerja Generator Fluks Aksial Magnet Permanen Putaran Rendah untuk Turbin Angin Sumbu Vertikal Tipe Savonius
}

\author{
Deni Susanto ${ }^{1}$, Mulyadi ${ }^{1}$, Nailul 'Atifah ${ }^{1}$, dan Perdamean Sebayang ${ }^{2, *}$ \\ ${ }^{I} J u r u s a n$ Teknik Mesin, Fakultas Teknik Universitas Pamulang, Tangerang Selatan \\ ${ }^{2}$ Pusat Penelitian Fisika - LIPI, Gd. 440 Kawasan PUSPIPTEK, Tangerang Selatan, Indonesia \\ E-mail: *sebayang.perdamean@gmail.com
}

Masuk:14 Februari 2018 Direvisi : 20 April $2018 \quad$ Disetujui : 11 Juni 2018

\begin{abstract}
Abstrak: Telah dilakukan perancangan dan pengujian pembangkit listrik tenaga angin menggunakan turbin angin sumbu vertikal tipe savonius dan generator magnet permanen fluks aksial. Turbin angin savonius dapat bekerja pada kecepatan angin yang rendah, menangkap angin dari segala arah, dan memiliki kontruksi yang sederhana. Generator fluks aksial yang dirancang menggunakan 8 buah magnet permanen jenis Neodymium Iron Boron $(\mathrm{NdFeB})$ dan 8 buah kumparan kawat tembaga berdiameter $0,5 \mathrm{~mm}$. Hasil pengujian pembangkit listrik tenaga angin mampu menghasilkan output yang stabil pada kecepatan angin minimum $2 \mathrm{~m} / \mathrm{s}$ dengan rentang pengujian 1-5 m/s. Turbin angin memiliki nilai Rotor Power Coefficient (Cpr) rata-rata 0,158. Generator aksial mampu menghasilkan tegangan sebesar 4,5 V dan arus $5 \mathrm{~mA}$ dengan daya 0,0225 Watt pada kecepatan angin $1 \mathrm{~m} / \mathrm{s}$ serta menghasilkan tegangan $34,7 \mathrm{~V}$ dan arus $147 \mathrm{~mA}$ dengan daya 5,1 Watt pada kecepatan angin $5 \mathrm{~m} / \mathrm{s}$. Energi listrik yang dihasilkan generator disimpan dalam akumulator. Energi listrik yang tersimpan dikonversikan agar dapat digunakan pada beban berdaya rendah.
\end{abstract}

Kata kunci: Turbin angin, savonius, generator fluks aksial, kecepatan putar, tegangan, arus, daya

Abstract: The design and performance analysis of wind power plants has been done using a vertical axis type savonius wind turbine and a permanent magnetic flux generator. Savonius wind turbines can work at low wind speed, catch wind from all direction, and have simple construction. The axial flux generator was designed by using 8 pieces of Neodymium Iron Boron $(\mathrm{NdFeB})$ permanent magnets and 8 coils of $0.5 \mathrm{~mm}$ diameter copper wires. The wind power plant test result was capable to produce stable output at minimum $2 \mathrm{~m} / \mathrm{s}$ wind speed. The wind turbine has $0,158 \mathrm{Cpr}$ value. The generator was able to produce $4.5 \mathrm{~V}$ voltage and $5 \mathrm{~mA}$ current with 0,02 Watt power at $1 \mathrm{~m} / \mathrm{s}$ wind speed and produce $34,7 \mathrm{~V}$ voltage and $147 \mathrm{~mA}$ current with 5,1 Watt power at $5 \mathrm{~m} / \mathrm{s}$ wind speed. The electrical energy generated by the generator was stored in the accumulator. The stored electrical energy was converted to be used in low-power load.

Keywords: Wind turbine, savonius, axial flux generator, rotational speed, voltage, current, power

\section{PENDAHULUAN}

Kebutuhan energi listrik di Indonesia terus meningkat seiring dengan berkembangnya pembangunan dan pertambahan penduduk. Hal tersebut memicu terjadinya krisis energi terutama pada bahan bakar fosil yang masih menjadi sumber energi utama. Selain itu penggunaan bahan bakar fosil secara terus-menerus akan menimbulkan masalah pencemaran lingkungan. Untuk menanggulangi hal tersebut maka banyak peneliti yang mengembangkan penggunaan sumber energi lain yang lebih ramah lingkungan. Salah satu pemanfaatan sumber energi alternatif adalah pembangkit listrik tenaga angin. Potensi energi angin di Indonesia cukup memadai untuk pembangkit listrik karena kecepatan angin rata-rata di Indonesia berkisar antara 3,5-7 m/s. Melihat potensi wilayah pantai Indonesia yang cukup luas, pemanfaatan tenaga angin sebagai sumber energi terbarukan di Indonesia sangat mungkin untuk dikembangkan [1].

Berbagai macam penemuan turbin angin sebagai pembangkit listrik sudah ditemukan sejak lama dengan berbagai macam bentuk desain turbin baik horizontal maupun vertikal. Turbin angin vertikal tipe savonius adalah 
salah satu macam turbin angin yang mempunyai kelebihan yaitu dapat bekerja pada kecepatan angin yang rendah, menangkap angin dari segala arah, dan memiliki kontruksi yang sederhana. Bentuk sudu dibuat sedemikian rupa sehingga dapat menghasilkan gaya dorong yang akan memutar generator [2].

Beberapa penelitian yang telah dilakukan sebelumnya menggunakan variasi kontruksi yang berbeda-beda, antara lain dengan memvariasikan jenis turbin, jumlah sudu, celah udara, dan jenis generator. Penelitian mengenai generator magnet permanen putaran rendah 3 fasa tipe aksial dengan menggunakan magnet permanen jenis $\mathrm{Fe}$ pada putaran $100 \mathrm{rpm}$ sampai $700 \mathrm{rpm}$ dihasilkan tegangan AC 2,7 volt sampai 33,33 volt. Semakin cepat putaran, semakin besar tegangan yang dihasilkan. Pada pengisian akumulator, pada putaran $300 \mathrm{rpm}$ generator sistem 3 fasa hubung bintang menghasilkan tegangan 12,91 volt DC dan arus 0,16 A. Pada putaran 500 rpm, sistem 3 fasa hubung bintang menghasilkan tegangan 13,73 volt DC dan arus 2,9 A. Sedangkan sistem tiga fasa hubung delta menghasilkan tegangan 12,9 volt DC dan arus 1,1 A [3].

Berdasarkan permasalahan dan studi pustaka yang telah dilakukan maka dirancang suatu pembangkit listrik tenaga angin menggunakan turbin angin sumbu vertikal (TASV) tipe savonius dengan 8 sudu turbin dan generator magnet permanen fluks aksial (MPFA) dengan satu rotor dan satu stator (single side). Generator yang dibuat menggunakan 8 magnet permanen jenis $\mathrm{NdFeB} \mathrm{NdFeB} \mathrm{berukuran} 5 \mathrm{~cm}$ x $4 \mathrm{~cm}$ x $1 \mathrm{~cm}$ dan 8 kumparan masingmasing terdiri dari 400 lilitan. Pemilihan generator jenis ini paling cocok digunakan untuk turbin angin sumbu vertikal karena memiliki tingkat efisiensi yang tinggi. Pengujian dilakukan dengan memvariasikan kecepatan angin mulai dari $1 \mathrm{~m} / \mathrm{s}$ sampai dengan $5 \mathrm{~m} / \mathrm{s}$.

\section{METODOLOGI}

Perancangan pembangkit listrik tenaga angin dimulai dengan melakukan studi literatur. Hasil studi literatur tersebut digunakan sebagai dasar penentuan geometri dan spesifikasi pembangkit listrik tenaga angin yang dirancang. Desain rancangan ini terdiri dari dua komponen utama yaitu turbin angin savonius dan generator magnet permanen. Hasil dari perancangan yang telah dilakukan ditunjukkan pada Gambar 1. Berdasarkan data dan spesifikasi pembangkit listrik yang telah dibuat, dapat diketahui nilai tip speed ratio (TSR), rotor power coefficient (Cpr), daya mekanik turbin angin (P), kerapatan fluks magnet maksimum (Bmax) fluks maksimum ( $(\max )$ frekuensi (f), dan tegangan induksi (Erms).

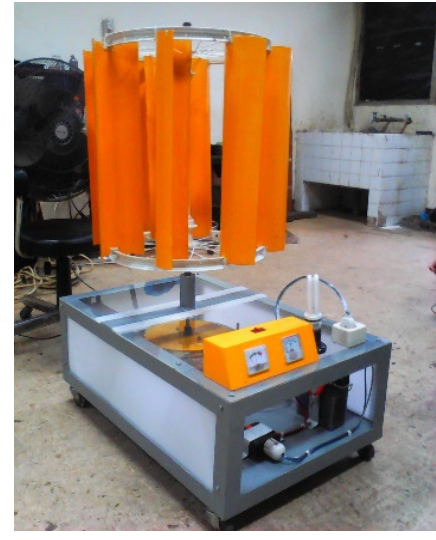

(a)

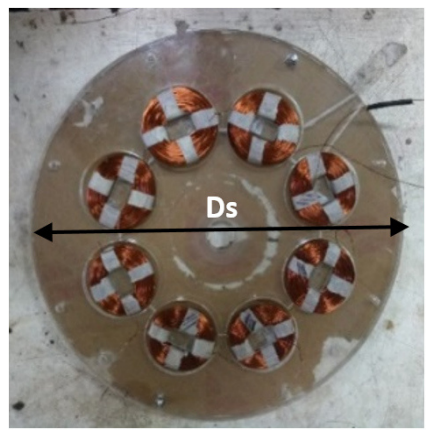

(b)

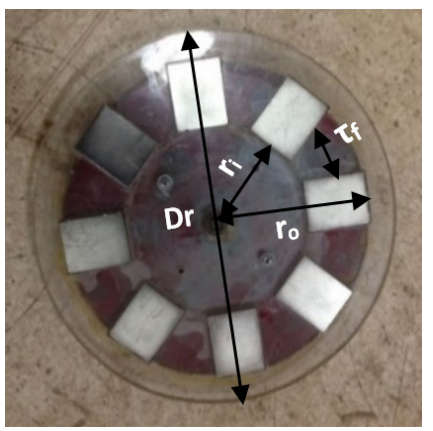

(c)

Gambar 1. Hasil perancangan (a) pembangkit listrik tenaga angin (b) stator generator dan (c) rotor generator

Dalam eksperimen, pembuatan pembangkit listrik tenaga angin dilakukan mulai dari perancangan perangkat keras yaitu turbin angin, dudukan turbin, dan generator aksial. Pada generator digunakan magnet permanen dengan kerapatan fluks magnet sebesar 0,3862 Tesla berbentuk rectangular yang dipasang menggunakan cara embedded.

Setiap jenis turbin angin memiliki faktor Tip Speed Ratio yang berbeda-beda. Tip Speed Ratio (TSR) adalah rasio kecepatan ujung rotor terhadap kecepatan angin bebas. Tip Speed Ratio dapat dihitung dengan menggunakan persamaan [5]:

$$
T S R=\frac{\pi \cdot D \cdot n}{60 . v}
$$


14 | Deni Susanto, dkk., Rancang Bangun dan Analisa Kinerja Generator ....,

Dengan mengetahui nilai TSR maka dapat ditentukan nilai Rotor Power Coeficient (Cpr) menggunakan grafik berikut ini:

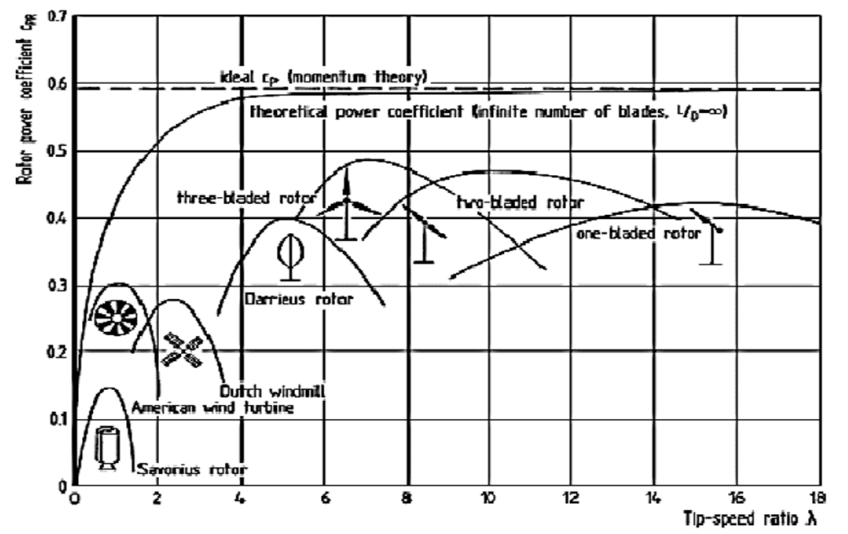

Gambar 2. Hubungan Koefisien Daya (Cpr) dan TSR pada Turbin Angin [7]

Dengan memasukkan nilai Rotor Power Coeficient (Cpr) maka daya mekanik aktual turbin angin (P) yang dapat diperoleh dari energi angin ditentukan dengan persamaan:

$$
P=C p r \cdot \frac{1}{2} \cdot \rho \cdot A \cdot v^{3}
$$

Dimana A adalah luas sapuan permukaan blade turbin $\left(\mathrm{m}^{2}\right), \mathrm{v}$ adalah kecepatan angin $(\mathrm{m} / \mathrm{s})$ dan $\rho$ adalah massa jenis udara $\left(\mathrm{kg} / \mathrm{m}^{3}\right)$.

Tabel 1. Data Spesifikasi Pembangkit Listrik Tenaga Angin

\begin{tabular}{|c|c|c|c|}
\hline No & Parameter & Lambang & Nilai \\
\hline \multirow[t]{5}{*}{1} & Turbin Angin & & \\
\hline & - Diameter sudu turbin & $\mathrm{D}$ & $10,16 \mathrm{~cm}$ \\
\hline & - Panjang sudu turbin & $\mathrm{L}$ & $50 \mathrm{~cm}$ \\
\hline & - Jumlah sudu turbin & $\mathrm{N}$ & 8 buah \\
\hline & - Diameter Rotor turbin & $D_{\mathrm{rt}}$ & $43,18 \mathrm{~cm}$ \\
\hline \multirow[t]{8}{*}{2} & Rotor Generator & & \\
\hline & - Diameter rotor & $D_{\mathrm{r}}$ & $28 \mathrm{~cm}$ \\
\hline & - Jumlah magnet & $\mathrm{N}_{\mathrm{m}}$ & 8 buah \\
\hline & - Dimensi magnet & $\mathrm{p} \times 1 \times \mathrm{t}$ & $5 \mathrm{~cm} \times 4 \mathrm{~cm} \times 1 \mathrm{~cm}$ \\
\hline & - Jarak magnet & $\tau_{\mathrm{f}}$ & $3,58 \mathrm{~cm}$ \\
\hline & - Kerapatan fluks magnet permanen & $\mathrm{Br}$ & $0,3862 \mathrm{~T}$ \\
\hline & - Jari-jari luar magnet & $\mathrm{r}_{\mathrm{o}}$ & $12 \mathrm{~cm}$ \\
\hline & - Jari-jari dalam magnet & $\mathrm{r}_{\mathrm{i}}$ & $7 \mathrm{~cm}$ \\
\hline 3 & Stator Generator & & \\
\hline
\end{tabular}


Lanjutan Tabel 1.

\begin{tabular}{|c|c|c|c|}
\hline & - Diameter stator & $\mathrm{D}_{\mathrm{s}}$ & $33 \mathrm{~cm}$ \\
\hline & - Jumlah kumparan & $\mathrm{N}_{\mathrm{s}}$ & 8 buah \\
\hline & - Jumlah lilitan & $\mathrm{N}$ & 400 \\
\hline & - Jumlah fasa & $\mathrm{N}_{\mathrm{ph}}$ & 1 \\
\hline 4 & Jarak celah udara & $\delta$ & $0,5 \mathrm{~cm}$ \\
\hline
\end{tabular}

\section{HASIL DAN PEMBAHASAN}

Pengujian yang dilakukan pada pembangkit listrik menghasilkan beberapa data diantaranya kecepatan angin, kecepatan putar, tegangan listrik, dan arus listrik. Gambar 3 menunjukkan data yang didapatkan dari pengujian pembangkit listrik.

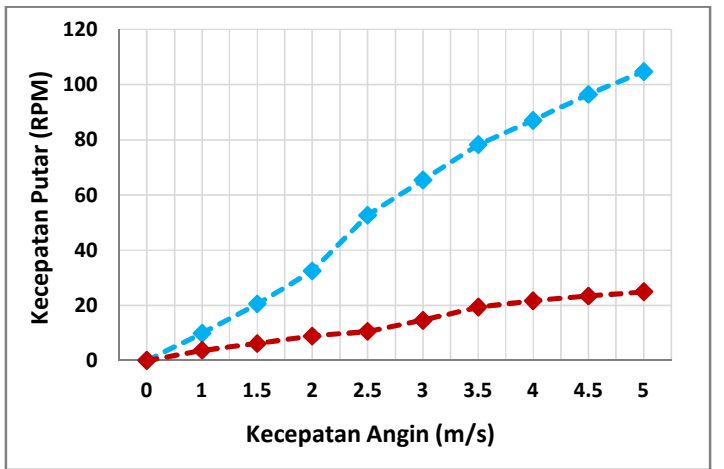

(a)

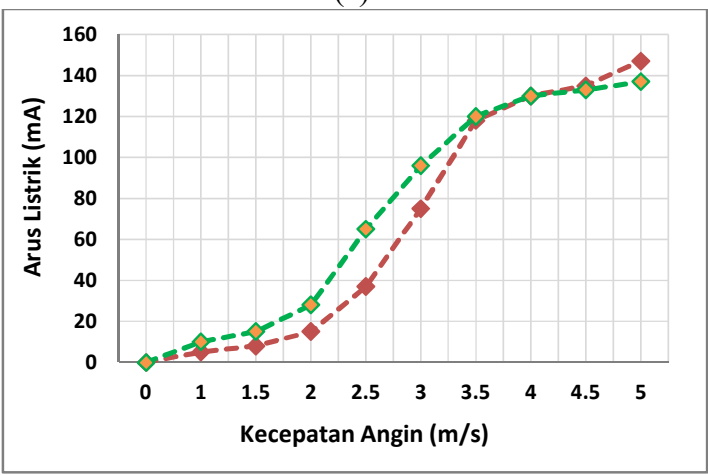

(c)

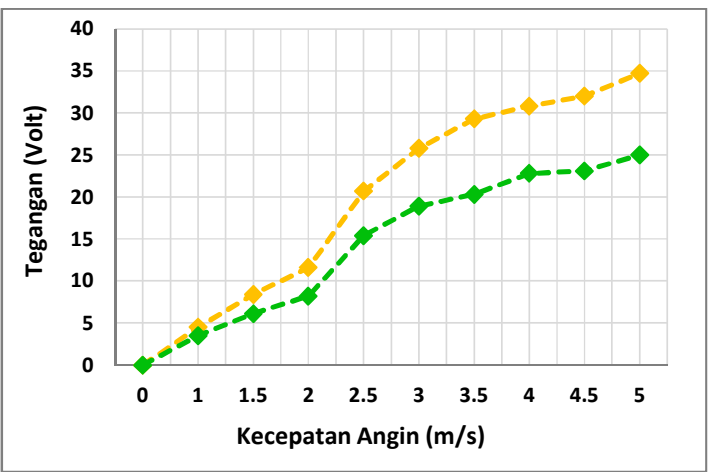

(b)

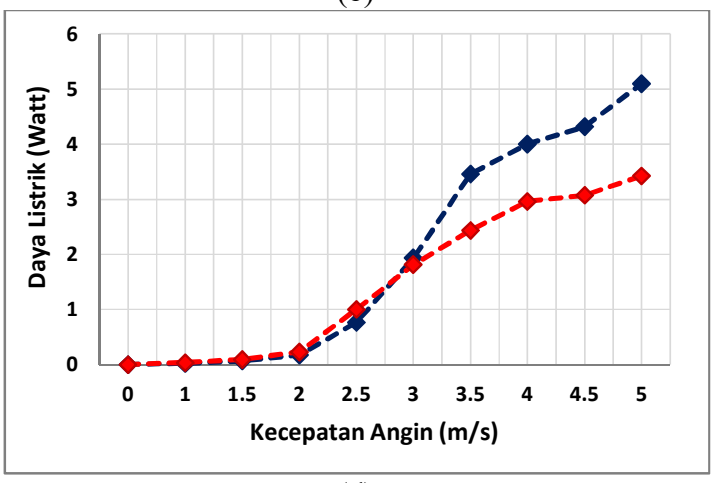

(d)

Gambar 3. Pengaruh variasi kecepatan angin terhadap (a) kecepatan putar turbin angin (atas) dan rotor generator (bawah), (b) tegangan output generator, (c) arus listrik output generator, dan (d) daya listrik output generator. Keterangan 3(b), (c), (d) : AC ( kurva atas) dan DC ( kurva bawah)

Pada Gambar 3 ditunjukkan pengaruh variasi kecepatan angin terhadap turbin angin dan generator aksial. Dari Gambar 3(a), pada kecepatan angin $1 \mathrm{~m} / \mathrm{s}$ turbin angin dapat berputar dengan laju putaran minimum sebesar 9,9 RPM. Sedangkan kecepatan putaran turbin angin maksimum yang dapat dihasilkan adalah sebesar 104,7 RPM pada kecepatan angin $5 \mathrm{~m} / \mathrm{s}$. Hasil ini menunjukkan bahwa ketika laju angin berhembus pelan maka kecepatan putar turbin angin dan rotor generator sangat kecil, sedangkan ketika laju angin meningkat maka kecepatan putar dari turbin angin dan rotor generator juga meningkat. Hal tersebut dipengaruhi oleh besarnya daya mekanik yang dimiliki oleh angin menjadi semakin besar karena adanya peningkatan kecepatan angin yang berhembus mengenai turbi angin. 
Pengujian pada generator dilakukan untuk mengetahui output tegangan dan arus listrik bolak balik (AC) dan searah (DC). Untuk mendapatkan arus DC, pada keluaran generator dihubungkan dengan bridge rectifier yang mengubah arus bolak balik menjadi arus searah. Gambar 3(b) menunjukkan bahwa kecepatan angin (v) yang berhembus sangat berpengaruh terhadap tegangan listrik (V) yang dihasilkan oleh generator. Pada kecepatan angin $1 \mathrm{~m} / \mathrm{s}$ generator dapat menghasilkan tegangan AC sebesar 4,5 volt dan tegangan DC sebesar 3,5 volt. Sedangkan pada kecepatan angin $5 \mathrm{~m} / \mathrm{s}$ dihasilkan tegangan AC sebesar 34,7 volt dan tegangan DC 25 volt. Dan Gambar 3(c) menunjukkan bahwa kecepatan angin (v) yang berhembus sangat berpengaruh terhadap arus listrik (I) yang dihasilkan oleh generator. Pada kecepatan angin $1 \mathrm{~m} / \mathrm{s}$ generator dapat menghasilkan arus AC sebesar $5 \mathrm{~mA}$ dan arus DC sebesar $10 \mathrm{~mA}$. Sedangkan pada kecepatan angin $5 \mathrm{~m} / \mathrm{s}$ dihasilkan arus AC sebesar $147 \mathrm{~mA}$ dan arus DC $137 \mathrm{~mA}$.

Dengan mengetahui besarnya tegangan dan arus listrik maka dapat ditentukan besarnya daya listrik yang dihasilkan oleh generator melalui perhitungan menggunakan persamaan $\mathrm{P}=\mathrm{V}$ x I. Gambar 3(d) menunjukkan bahwa kecepatan angin (v) yang berhembus sangat berpengaruh terhadap daya listrik (P) yang dihasilkan oleh generator. Jika kecepatan angin yang berhembus semakin tinggi maka daya listrik yang dihasilkan oleh generator akan semakin besar. Daya listrik maksimal yang dibangkitkan oleh generator pada kecepatan angin $5 \mathrm{~m} / \mathrm{s}$ adalah sebesar 5,1009 watt untuk daya listrik AC dan 3,425 watt untuk daya listrik DC.

\section{KESIMPULAN}

Telah berhasil dirancang dan dianalisa sebuah pembangkit listrik tenaga angin putaran rendah yang menggunakan turbin angin sumbu vertikal (TASV) tipe savonius dan generator magnet permanen fluks aksial (MPFA). Turbin angin memiliki nilai Cpr rata-rata sebesar 0,158. Generator magnet permanen fluks aksial dapat menghasilkan tegangan dan arus listrik pada kecepatan angin dan putaran rotor yang rendah, yaitu pada kecepatan angin $1 \mathrm{~m} / \mathrm{s}$ dapat menghasilkan tegangan dan arus minimum sebesar 4,5 volt dan $5 \mathrm{~mA}$ dengan daya $0,0225 \mathrm{Watt}$, serta pada kecepatan angin $5 \mathrm{~m} / \mathrm{s}$ dapat menghasilkan tegangan dan arus maksimum sebesar 34,7 volt dan 147 mA dengan daya 5,1 Watt. Semakin tinggi kecepatan angin maka semakin besar tegangan, arus listrik dan daya yang dihasilkan oleh generator. Pembangkit listrik tenaga angin hasil perancangan ini dapat digunakan untuk mensuplai eralatan listrik berdaya rendah serta dapat digunakan sebagai suplai cadangan bila terjadi pemadaman listrik.

\section{DAFTAR PUSTAKA}

[1] Daryanto Y 2007 “Kajian Potensi Angin Untuk Pembangkit Listrik Tenaga Bayu.” Balai PPTAGG

[2] Aribowo A 2006 "Penelitian Karakteristik Aerodinamika Savonius Bersudu Banyak." Unit Uji LAPAN

[3] Nurhadi A "Perancangan Generator Putaran Rendah Magnet Permanen," Teknik Elektro, Universitas Diponegoro, Semarang.

[4] Mustofa, Notosudjono D dan Suhendi D 2014 "Perancangan Pembangkit Listrik Menggunakan Generator Magnet Permanen Dengan Motor DC Sebagai Prime Mover.” Jurnal Teknik Elektro, Fakultas Teknik Universitas Pakuan, Bogor

[5] Alqodri M F, Rustana C E dan Nasbey H 2015 "Rancang Bangun Generator Fluks Aksial Putaran Rendah Magnet Permanen Jenis Neodymium (NdFeB) Untuk Turbin Angin Sumbu Vertikal Tipe Double-Stage Savonius." Seminar Nasional Fisika, Fakultas MIPA Universitas Negeri Jakarta, Vol. 4

[6] Waluyo Jati D, Sukmadi T dan Karnoto "Perancangan Generator Fluks Aksial Putaran Rendah Magnet Permanen Jenis Neodymium (NdFeb) Dengan Variasi Celah Udara." Jurnal Teknik Elektro, Fakultas Teknik Universitas Diponegoro, Semarang.

[7] Hau E 2006 Wind Turbines Fundamentals, Technologies, Application \& Economics $2^{\text {nd }}$ Edition. Berlin. Springer.

[8] Eldrigde F R 1980 Wind Machine - Second edition. New York: Van Nostran Reinhold Company.

[9] Ginting D 2007 “Analisis Desain, Teknologi Dan Prestasi Turbin Angin.” Pusat Teknologi Dirgantara Terapan, LAPAN

[10] Sudirham S 2002 Analisis Rangkaian Listrik Penerbit ITB.

[11] Tipler P A Fisika untuk Sains dan Teknik - Jilid I (terjemahan) Jakarta: Erlangga

[12] Nanang R, Gunarto dan Sarwono E "Study Eksperimental Berbagai Macam Jenis Sudu Turbin Angin Sumbu Horisontal Skala Laboratorium." Jurnal Teknik Mesin, Fakultas Teknik Universitas Muhammadiyah Pontianak, Kota Pontianak.

[13] Dwiyantoro B A, Suphandani V dan Rahman 2015 "Studi Eksperimental tentang Karakteristik Turbin Angin Sumbu Vertikal Jenis Darrieus - Savonius.” Jurnal Teknik Mesin, Fakultas Teknologi Industri Institut Teknologi Sepuluh November, Surabaya 
[14] Hasan D S, Hantoro R dan Nugroho G 2013 "Studi Eksperimental Vertikal Axis Wind Turbine Tipe Savonius Dengan Variasi Jumlah Fin Pada Sudu." Jurnal Teknik Mesin, Fakultas Teknologi Industri Institut Teknologi Sepuluh November, Surabaya

[15] Aryanto F, Mara I M dan Nuarsa M 2013 "Pengaruh Kecepatan Angin Dan Variasi Jumlah Sudu Terhadap Unjuk Kerja Turbin Angin Poros Horizontal.” Jurnal Teknik Mesin, Fakultas Teknik Universitas Mataram, Mataram

[16] Mahendra B, Soenoko R dan Sutikno D "Pengaruh Jumlah Sudu Terhadap Unjuk Kerja Turbin Angin Savonius Type L.” Jurnal Teknik Mesin, Fakulas Tenik Universitas Brawijaya Malang, Malang 